\title{
The Problem Analysis of the Education Connection about " $3+4$ " Electrical Engineering and Automation Profession of Secondary Vocational-Undergraduate
}

\author{
Xuehua Jiang \\ School of Automation and Electrical Engineering \\ Linyi University \\ Linyi, China \\ jxhyx@163.com
}

\begin{abstract}
The connected training model of the secondary vocational-undergraduate " $3+4$ " between seven year, is a breakthrough connection training mode aiming at middle and higher vocational education in the new situation, which can achieve complementary education and related education between secondary vocational school and undergraduate course, which provide an important way for secondary vocational graduates to lead higher education. Taking electrical engineering major as an example, this paper probes into the constructive ideas and measures of " $3+4$ " through training mode in the effective connection of training objectives, curriculum system, curriculum content, curriculum standards, teaching resources ,teaching management and other aspects.
\end{abstract}

Keywords-Electrical engineering and automation specialty; " $3+4$ " secondary vocational -undergraduate training; Educational cohesion

\section{INTRODUCTION}

In 2013, Shandong province organized the pilot of the modern vocational education system about the project of secondary vocational and ordinary undergraduate " $3+4$ ", the main attempt was the docking between the national demonstrative vocational school and the municipal undergraduate college. The students who participated in " $3+$ $4 "$ project, studied in vocational school for the first 3 years, then passed the "transition test", and upgraded to the undergraduate level of undergraduate courses for 4 years. This kind of training mode provides secondary vocational students with the opportunity to further study and also enhances the attraction of secondary vocational education to recruit highquality students. However, the connection between secondary vocational school and ordinary undergraduate course is not simply the connection of educational background; it should include the cohesion of training objectives, the connection of professional settings and the connection of courses. In order to make the " $3+4 "$ model play its greatest benefit, we must solve the problem of the connection between secondary vocational education and general undergraduate education, and the core content is the two-way effective reform and connection

This research was supported by the teaching reform of Shandong province undergraduate Colleges in 2015(Item number: 2015M060) between secondary vocational education and undergraduate education.

According to the requirements of the "Shandong Provincial People's Government on speeding up the construction of modern occupation education system to adapt to economic and social development views" (Lu Zhengfa 2012 49) and the "Shandong Provincial Department of education on the occupation colleges and universities do a good job in 2014 through the pilot work of segmental culture " (Shandong high word 2013 No. 23), Department of education determine the pilot schools, profession and enrollment about the sectional training of vocational colleges and undergraduate colleges on 2014. The pilot of " $3+4$ " sectional training have16 secondary vocational schools, a total of 21 professional points, linking 10 undergraduate colleges and universities. Among them, Yantai shipbuilding industry school "mechanical and electrical equipment installation and maintenance" specialty and Linyi University "electrical engineering and automation" profession, since 2014 , the " $3+4$ " training mode of secondary vocational schools and ordinary undergraduate has been carried out, with an annual enrollment plan of 40 people. At present, the first batch of enrolled students has 39 people to enter the undergraduate section to study. To effectively run through professional training pilot, the key is to effective reform and achieve convergence of segmented education, follow the objective law of talent development, strengthen theintegrity, systematicness and relevance of the construction of vocational curriculum system, avoid duplication and split to course construction. 


\section{GRASP THE Key IsSUES, Highlight THE COHESION TRAINING}

\section{A. Correctly understand the objectives of personnel training in different stages}

Secondary vocational education and undergraduate education are two different levels of training .Training goal of vocational stage is mainly to reach goals, attention is paid to the proficiency in a particular line, the core is to train practical, skilled and operational talents. Training objectives and specifications of medium occupation education is to develop the early, middle and senior technical talents who are needed by the first line of production, construction, management, service. The secondary vocational period requires students to finish the learning of basic skills with the basic work of the industry. After graduation, students should have the professional ability to do the basic work of the industry. However, training goal of undergraduate stage is to cultivate the senior technical talents training of high level, application, and management. That is directly to train the professional talents of senior technicians and engineers who are needed by particular post. The cultivation of students takes vocational skills and comprehensive quality on employment position as the main line to construct theoretical curriculum and practical curriculum system, carrying out the combine teaching process with working process, combine curriculum standards with national professional standards to train students' professional ability and sustainable development ability and to have the ability to be competent for higher technical content when they graduate [1].

\section{B. Pay attention to the holistic innovation of talent training}

The two stages of " $3+4$ " have different training objectives, which determine the different forms of education, the content of the course, the concept of personnel training and so on, which need to be treated differently. Compared with the secondary vocational education, the undergraduate pays more attention to the cultivation of creativity, and in the means of education and education mode, it must also adapt to the undergraduate training objectives of vocational education, and cultivate the students' innovative spirit and the ability of practical application. This training mode should be based on innovative design as an important carrier, according to the goal of personnel training, to design through training way. The teaching process should be combined with the reality, the market, the industry, and the enterprise; We should construct the knowledge innovation system, teaching innovation system and personality innovation system which accord with the training target of professional innovative talents; We should explore the mode from theoretical research, teaching concept, personnel training mode, curriculum set, teaching methods, teaching management, student management, scientific research project and carry through innovative, integrated design and practice to the training process of " $3+4$ " applied talents [2]

\section{Through Training Program, Pay AtTention to TEACHING COHESION}

\section{A. Cohesion of training objectives}

Doing "3+4" education and achieving training objectives, we pay more attention on the link of training objectives, which is favor for combining vocational and undergraduate education. This two aspects can make cohesion contributes, which form a cohesive force to make the talent training mode reach to optimize effectiveness. Specifications for personnel training of "mechanical and electrical equipment installation and maintenance" specialty in Yantai shipbuilding industry school is to cultivate the skilled application talents who have basic literacy, the ability to continue learning and team spirit, and have good professional ethics, mastering the necessary basic knowledge of culture, professional knowledge and professional skills, then can engage in the intermediate occupation of mechanical and electrical equipment repair. However, specifications for personnel training of "electrical engineering and automation" profession in Linyi University is to cultivate applied talents of engineering technology who master the systematic basic theory and professional knowledge, and have solid professional quality, strong practical skills and the ability of analysis to solve practical engineering problems. For the electric power enterprises and equipment manufacturing enterprises, students can engage in electrical engineering hardware assembly, electrical mapping and design and the development, application and management work about the application of electrical engineering, and has excellent development potential of engineers. In order to achieve the continuity of training objectives, secondary vocational and undergraduate schools need to work out a reasonable talent training program, which is the first step to achieve the effective convergence of the two stages of curriculum [3].

\section{B. The connection of curriculum system}

We consider the connection between secondary and undergraduate in the trial stage and the state has not uniform curriculum standards, no more than curriculum system integration design. Course content are always repeated and the wrong problems has appeared in connected courses such as disjointed cultural curriculum, repeated professional theoretical basis curriculum, professional skills curriculum upside down, mismatched theory class and practice class etc. So, they would have done a lot of researches and comprehensive communication in cooperation, in order to avoiding the phenomenon of lack of coordination in the curriculum. On this basis, we completed the design of 7 year curriculum system. Curriculum design will be divided the 7 years into two stages, namely, secondary vocational and undergraduate stages. Each stage has general education courses, professional required courses, and professional elective courses, centralized practical teaching courses, which stage pays attention to the advantages of the school, the differences of the students' quality, the basic and complementary cohesion of the course. The overall consideration of curriculum is given, and the curriculum system is integrated. In order to avoiding the disjointed phenomenon of the cultural basic courses in vocational education, secondary vocational education strengths the cultural basic course teaching, especially having the impact 
of the subjects of some of the larger follow-up courses, such as Chinese, mathematics, physics, English. We choose the school textbooks and require to the degree of general high school students through teaching [4].

\section{The connection of curriculum standards}

The curriculum standard of secondary vocational education is a teaching guidance document that stipulates the course nature, curriculum objectives, content goals and implementation proposals of a subject. Compared with the teaching program, criterion for curriculum details the course of the basic concept, curriculum objectives, curriculum implementation suggestions clearly, especially the problem of putting forward "why to teach" and "teach to what extent of ".The basic requirements of learning for all students are proposed. In the process of transition and vocational undergraduate curriculum, we put the teaching contents of two stages in a unified course within the framework which are understood and set and formulate a unified curriculum standard, providing reference and guidance for curriculum development. The electrical section of the secondary vocational education and "circuit analysis" course of undergraduate segment as an example, in the DC circuit part, from the vocational students' cognitive level of understanding about the simple circuit by DC circuit to the complex circuit, there is mainly to let students understand the basic structure of the circuit and simple calculation; In the undergraduate section about DC circuit, starting from the analysis of the equivalent circuit model, we study the general analysis method of transform circuit, and then further study circuit theorem. The purpose is mainly that students can master the basic theory and calculation method of linear circuit analysis and are trained its strong application. So, the curriculum structure level is clear and we can effectively achieve the coherence of curriculum content and communication, so as to avoid the phenomenon of secondary and higher education courses in the course of each array, fuzzy positioning, and convergence [5].

\section{The connection of curriculum content}

There is duplication between course content of secondary vocational and ordinary undergraduate. According to the statistics, the repetition rate of the curriculum system and teaching content of the same major in some secondary vocational and universities is over $30 \%$, especially the professional basic courses. Electrician foundation course of secondary vocational mainly includes circuit composition, DC circuit, capacitor, magnetic field and electromagnetic induction, single-phase AC circuit, three-phase AC circuit. The circuit analysis of undergraduate mainly includes the circuit model, circuit principle, circuit equivalent transform, general circuit analysis, circuit theorem, energy storage element, the phase measurement of one order and two order circuit time domain analysis, sinusoidal steady state circuit analysis, the frequency response of the circuit, three-phase circuit. A lot of content is coincident, but the degree is different for students. Students are required to know the basic concept of secondary circuit, analyze and calculate the simple circuit, and focus on the simple application of electrician foundation knowledge and skills point to lay a solid foundation for the follow-up courses of the professional learning. But undergraduates are required to master the application of the theoretical basis of circuit knowledge source, principle analysis, formula deduction and complex calculation with application of higher mathematics methods. Therefore, the " $3+4$ " course must communicate with the content overlap, and integrate the teaching content. Undergraduate class hours are reduced and the goal is set up for the similar professional courses [6].

\section{STRENGTHEN OVERALl COORDINATION AND ENSURE COHESION MEASURES}

\section{A. Cohesion of teaching staff}

The construction of teaching staff is the key to ensure the integration of " $3+4$ " and the quality of training. We should strengthen the communication and cohesion of professional teachers in cooperative colleges, and establish joint training, two-way flow and sharing mechanism of teachers. This training mode should focus on "double qualified" teachers, and guide vocational schools, universities and enterprises to build a training base for teachers. Colleges and universities should actively carry out teacher training programs, encourage teachers to further their study, take exercise attachment to the enterprise, promote teachers to update educational concepts and enhance teachers' engineering practice ability, improve the teaching level of teachers' professional skills, and a variety of ways to increase the training and introduction of "double qualified" Teachers. Through the integration of school and enterprise, colleges and universities should build a "double qualified" teacher training base, perfect teachers regularly to enterprise practice system. Furthermore, colleges and universities should employ professional and technical personnel with practical experience and highly skilled talents as part-time teachers. In order to improve the proportion of "double qualified" teachers and establish a teacher team suitable for " $3+4$ " undergraduate vocational education mode, teachers should be encouraged to participate in the training and examination of senior technical qualification certificates held by the relevant departments of the state.

\section{B. Cohesion of teaching resources}

In terms of teaching resources, through the integration of existing professional education resources, we can realize the sharing of educational resources in cooperative Colleges, give full play to the existing teaching resources in the cultivation of students' practical ability in Engineering, highlight practical teaching and the cultivation of professional ability, improve the quality of professional personnel training, and ensure the smooth implementation of pilot projects. At the same time, we need to build virtual simulation laboratory, student innovation training laboratory, discipline competition training room and so on. A certain number of comprehensive, design and innovative experiments should be established to ensure the time and quality of curriculum design, comprehensive training and graduation design. We should emphasize the integration of production and teaching, strengthen school enterprise cooperation, establish a practice base outside school, organize centralized probation and practice as much as possible, to meet the requirements of students' on-site teaching and internship. With the combination of students' theory and practice, the 
vocational training and operation skills are improved from the production practice, at the same time to meet the professional teachers' enterprise practice exercise and participate in technical transformation and new technology development [7].

\section{Cohesion of teaching management}

In order to ensure the smooth progress of the pilot project, it is necessary to strengthen the connection of teaching management. According to the requirements of professional skills in electrical engineering and automation, curriculum standards for each course should be formulated by our professional team between schools, and organize the teaching according to the curriculum standard strictly in the course of teaching. We should establish the mechanism of teaching quality supervision and assessment, strengthen process monitoring. In the teaching progress, teaching methods, assessment, evaluation and other aspects can get orderly arrangements and cohesion. The problems in the teaching process are discussed and solved in time. In addition to Chinese, mathematics, English and physics, the core basic course of secondary vocational school need the 5-6 main courses according to the importance of curriculum support for professional learning. Professional team of the two schools develop each course curriculum standards which is strictly done accordance with the curriculum standards in the teaching process .If there are serious discrepancies between teaching content with curriculum standards of the early formation, we must promptly adjust and explain. Phased teaching threedimensional target is developed with refinement knowledge, ability and quality to promote the connection of secondary undergraduate teaching orderly, and break through source of theory, ensure learning and application for the future. The curriculum examination, examination time and examination paper secrecy of course examination should be provided. The track of personnel training is improved persistently with the professional team of two schools.

\section{CONCLUSIONS}

The pattern of " $3+4$ " vocational-Bachelor cohesion is a new thing, which can realize complementary education, cohesion education and related education of the vocational and undergraduate education. It provides an important way to the high level of education for secondary vocational school graduates and provides a good ladder for improving comprehensive ability and enhancing the occupation development potential. At the same time, it also provides a new talent training mode for colleges and universities to cultivate versatile talents with strong practical ability and good theoretical foundation

\section{ACKNOWLEDGMENT}

This research was supported by the teaching reform of Shandong province undergraduate Colleges in 2015(Item number: 2015M060)

\section{REFERENCES}

[1] H. Xu, Y. Zhang, and W, Jin, "Exploration and Practice on Curriculum Connection Based on " $3+4$ " Training Mode,", Journal of Changzhou Institute of Technology, vol. 28, no.1, pp. April 2015.

[2] X. Jiang, "The Exploration and Practice of the " $3+4$ " Training Mode," Journal of Linyi University, vol. 38, no. 5, pp. 129-134, October 2016.

[3] X. Jiang, and P. Chen, "Research on " $3+4$ " Consistent and Segmented Training Mode for Second Vocational to Undergraduate in Engineering Majors," Advances in Social Science, Education and Humanities Research, vol. 69, pp. 987-99, July 2016.

[4] X. Xie, "An Investigation and Analysis on the Link at Two Stages of "3+2" Type Vocational Education -A Case Study of Wenzhou Vocational \& Technical College," Journal of Wenzhou Vocational \& Technical College, vol. 9, no.4, pp. 28-32, Decembe, 2009.

[5] Z. Sun, "Research into the " $3+2$ " stage training of financial management professionals of higher vocational majors and application - oriented graduates," Journal of Xinyu University, vol. 19, no. 5, pp. 137-139, October 2014

[6] Q. Chen, and S. Yang, "On the Practice of $3+4$ Organic Link Model of Secondary Vocational Applied Undergraduate," Journal of Inner Mongolia University of Finance and Economics, vol. 15, no. 37, pp.131134, 2017.

[7] Y. Zhang, "Vocational Education Integration Research Based on " $3+$ 4" odel," Journal of Shandong Institute of Commerce and Technology, vol. 14, no. 1, pp. 51-53, February 2014. 